\title{
ROOT STABILITY IN HYBRID LASER WELDING
}

\author{
Wojciech Suder ${ }^{1}$, Supriyo Ganguly ${ }^{1}$, Stewart Williams ${ }^{1}$, Bagus Yudodibroto ${ }^{2}$ \\ ${ }^{1}$ Welding Engineering and Laser Processing Centre, Cranfield University, Cranfield, MK43 OAL, \\ UK \\ ${ }^{2}$ Heerema Marine Contractors, Leiden, 2332 AA, The Netherlands
}

\begin{abstract}
Hybrid laser welding offers promising advantages over the traditional arc-based welding processes. The high penetration ability of lasers and the filler wire delivery of gas metal arc welding (GMAW) enable joining of thick section materials without the need of multi-pass. The output power of modern solid state lasers provides enough energy to penetrate thicknesses exceeding $20 \mathrm{~mm}$ in steel. However, the high aspect ratio fusion zone with the rapid solidification does not always provide beneficial conditions for achievement of good weld profiles. Distribution of the liquid metal between the top and root sides of a joint, and hence the weld profile, are determined by a complex balance between the vaporization pressure of a laser, the electromagnetic force of an arc and the surface tension of a meltpool. In this work, the stability of root profile and all aspects related to the achievement of acceptable roots in pipeline welding have been investigated. It has been found that in order to achieve a smooth root profile in deep penetration hybrid laser welding, not only a sufficient penetration force, but also a certain amount of energy need to be provided. This is required to maintain the keyhole fully developed with a steady state pressure balance throughout the thickness. It is also important to achieve sufficient temperature in the root and to provide appropriate wetting between the liquid metal and the back surface of the material. Depending on the power density and energy used, different regimes were identified with sagging of the root in the initial stage, followed by good quality root profiles and then ending on excessive melt expulsion with further increase of power density. The results suggest that if operated in the right regime, the process is very tolerant, in terms of energy and power density required for acceptable root profiles and good quality joints can be achieved.
\end{abstract}

Keywords: Laser hybrid welding, pipe welding, melt flow, root formation

\section{Introduction}

Hybrid laser arc welding, thanks to the combination of deep penetration ability of lasers and deposition of filler wire of gas metal arc welding, offers higher productivity and lower distortion than arc welding and better weld profile than laser welding. The bead profile and penetration depth can be controlled almost independently by changing the wire feed speed (WFS) and the energy input from arc and laser. The additional heat input of the arc source broadens the top part of the fusion zone, delays the solidification and provides the molten filler metal, which is consumed for generation of the weld bead [1-3]. The hybrid process enables deep penetration and high processing speeds and results in relatively low residual stresses and distortions [4]. 
Hybrid laser welding is more complex than laser or arc welding. There are many aspects that influence weld profile, microstructure and mechanical properties. Keyhole is the result of a dynamic balance between the metal vapours pressure and the surface tension, which is dependent on the material type, temperature and concentration of oxygen [5-8]. The meltpool, which surrounds the keyhole is subject to a continuous flow caused by the temperature gradient, Marangoni convection, drag force of escaping vapours and the capillary flow due to the welding speed [9-12]. In addition the electromagnetic pressure of arc and the momentum of droplets induce additional components to the flow of the liquid metal in hybrid welding [13, 14]. Because it is highly dynamic system it is more difficult to achieve a good balance between those forces, which is necessary for stable weld profiles and this becomes more challenging as the thickness of the material increases.

Achieving a good root profile with a smooth transition between the weld metal and the base plates is a necessary requirement in structural welds. The quality of weld profile can be one of the main factors when selecting a welding process for a structural component. It has been shown that it is difficult to optimise the hybrid process in such a way to achieve perfect root and top bead profile at the same time $[15,16]$. This motivated development of a multi-pass laser welding [17-19]. Havrilla et al. compared welding performance between a $\mathrm{CO}_{2}$ laser and a disc laser and showed that with the $1 \mu \mathrm{m}$ wavelength laser the processing window for stable root profiles was quite narrow. When laser power was insufficient or too high significant melt ejection and undercut were observed. In contrast, with the $\mathrm{CO}_{2}$ laser such a phenomenon was not observed and a much wider processing window for stable root was reported, which was attributed to the difference in Brewster angles between the lasers. However the optical setups and the focal positions were different, which could affect the experiments [20].

In this project stability of the root in $2 \mathrm{G}$ welding is investigated for a wide range of conditions. Temperature measurement and high speed imaging were used to monitor the formation of root in hybrid laser gas metal arc welding.

\section{Experiments}

A continuous wave $(\mathrm{CW})$ fibre laser with a maximum power of $8 \mathrm{~kW}$ was used. The optical set-up consisted of a $300 \mu \mathrm{m}$ optical fibre, a 125 $\mathrm{mm}$ collimation lens and a $250 \mathrm{~mm}$ focusing lens. This set-up resulted in a beam diameter of $610 \mu \mathrm{m}$ with a uniform top hat intensity distribution. All welds were carried out in focus position, i.e. the focal point was placed on the top surface of a bevel.

A Lincoln S355 gas metal arc welding (GMAW) power source with a maximum current of $350 \mathrm{~A}$ was used as the arc source. The GMAW source was operated in a pulsed synergic mode Rapid Arc. Argon mixture with $20 \%$ of $\mathrm{CO}_{2}$ was used as shielding gas, supplied at a rate of $17 \mathrm{l} / \mathrm{min}$. A mild steel filer wire ESAB OK Autrod 12.66, with a diameter of $1 \mathrm{~mm}$ was used. The voltage and current characteristics of each weld was acquired using a Yokogawa oscilloscope and the instantaneous power was calculated in each case.

The experimental set-up is shown in Figure 1 and Figure 2. In this configuration the laser head and the GMAW torch were stationary and the pipes were rotated on a pipe manipulator. In order to avoid any influence of the gravitational force the welding was carried out in $2 \mathrm{G}$ position (welding in horizontal position). All welds were made in the laser leading configuration with a laser-GMAW torch separation distance of approximately $2 \mathrm{~mm}$, as shown in Figure 3. The laser head was radial to the pipe rotation, whilst the GMAW torch was inclined at an angle of $30^{\circ}$ to the welding direction.

To investigate the root formation a camera based monitoring system was used. The camera was focused on the inner surfaces of pipes, as shown in Figure 4 . In addition a neutral density filter and a halogen illumination were used to enhance quality of the imaging.

Pipes with $17 \mathrm{~mm}$ wall thickness and $12 \mathrm{~mm}$ root face were used. The material was X65 pipeline steel. R-type thermocouples were used to monitor the thermal-cycles. The thermocouples were positioned at two different depth levels from the bottom of the bevel ( $2 \mathrm{~mm}$ and $5 \mathrm{~mm})$, as shown in Figure 5. 


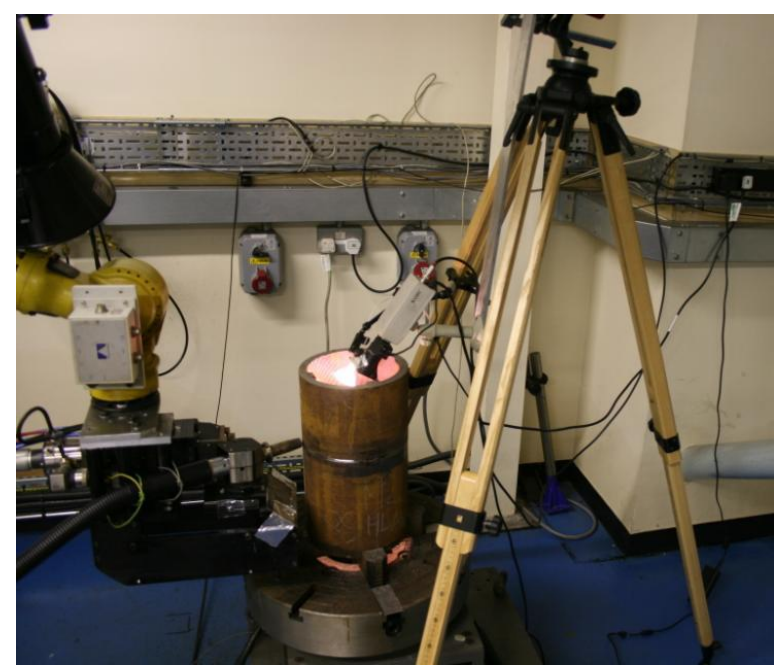

Figure 1: Experimental set-up

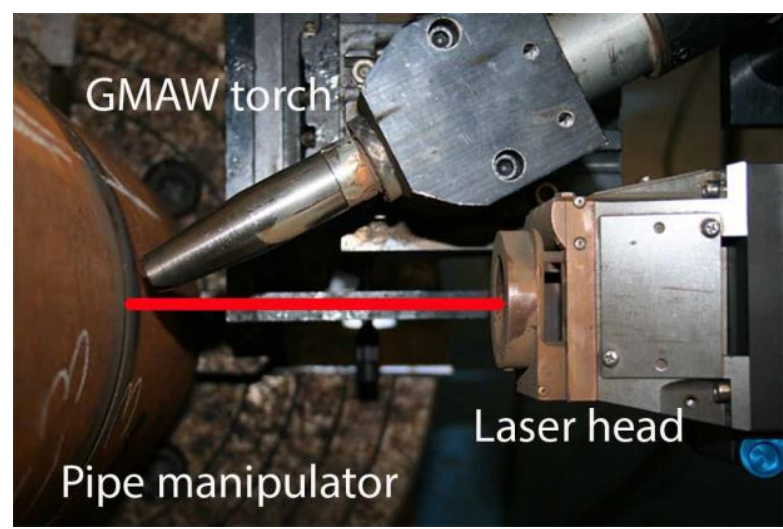

Figure 2: Experimental set-up (top view)

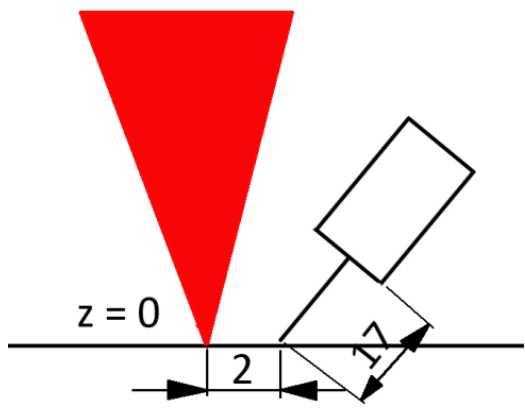

Figure 3: Schematics of laser and arc configuration

To minimise the error due to the positioning accuracy of the thermocouples, two thermocouples at different positions with a separation distance of $0.5 \mathrm{~mm}$ were attached at each depth. The thermocouples were resistance spot welded in appropriate positions by using precisely drilled channels, as shown in Figure 5. Ceramic inserts were used to ensure that each thermocouple was welded to the tapered tip of a drilled hole to ensure accuracy. Distribution of the drilled channels was designed based on initial welding experiments to ensure that temperature was measured as close as possible to the fusion zone, but without melting of the thermocouples.

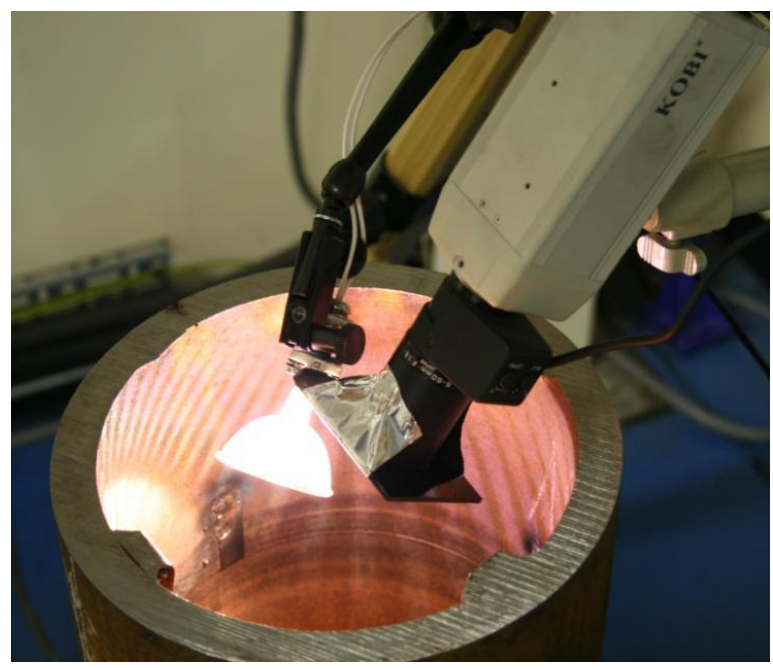

Figure 4: Camera set-up

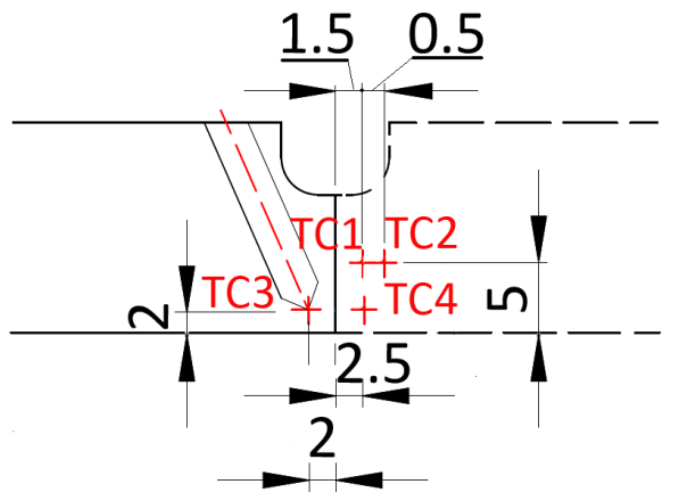

Figure 5: Position of thermocouples in bevel

Welding conditions were varied by changing the laser power and the arc power at constant laser beam diameter of $0.61 \mathrm{~mm}$ and welding speed of $1 \mathrm{~m} / \mathrm{min}$

\section{Results and discussion}

In Figure 6 image of a root for low energy conditions is shown. The laser beam could not 
break through and the plume is not visible, apart from a few spatters occasionally expelled from the meltpool. All the excessive metal was being lagged behind the heating zone and formed periodic instabilities, evident as humps. Macrograph and picture of this root, shown Figure 7, reveal significant undercut of the top bead and excessive penetration of the root. This suggests that all excessive metal deposited by the arc source has been pushed to the root side but not utilised for the formation of the weld bead and expelled out. This is attributed to insufficiently developed keyhole and insufficient temperature in the root.

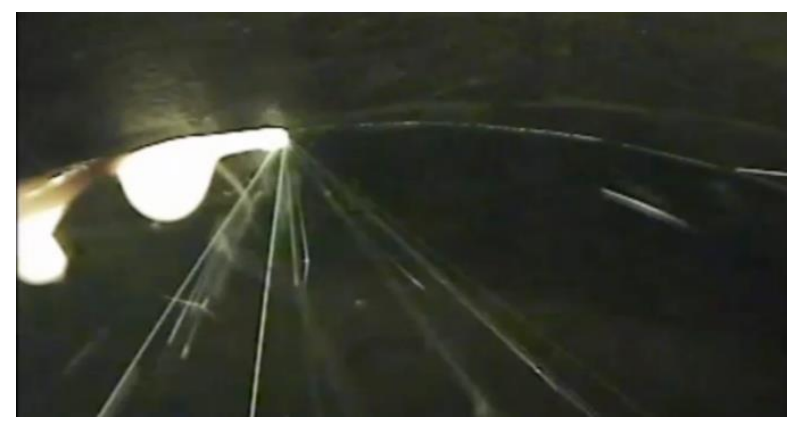

Figure 6: Root formation at $7.7 \mathrm{~kW}$ of laser power and 7.4 kW arc power (WFS $12 \mathrm{~m} / \mathrm{min}$ )

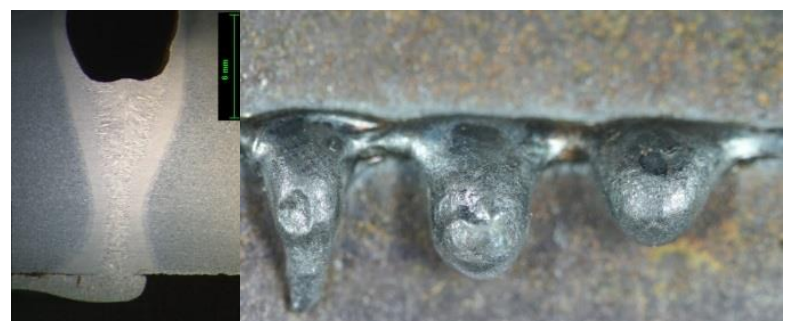

Figure 7: Macrograph and picture of root at $7.7 \mathrm{~kW}$ laser power and $7.4 \mathrm{~kW}$ arc power (WFS $12 \mathrm{~m} / \mathrm{min}$ )

In normal conditions of hybrid laser arc welding the laser induced recoil pressure develops a keyhole and the arc source provides the filler metal and the additional heat which is continuously transported with the liquid metal to the bottom of the joint. This heat is used to form the root profile. But if the energy is insufficient this results in instabilities, similar to those in Figure 6. This is explained schematically in Figure 8. In that case there was not enough energy to keep the full penetration to balance the pressure and to transport enough heat to the root. This is related to undeveloped keyhole which is inclined and fluctuates periodically and only brakes through intermittently. With each burst a large amount of the liquid metal is delivered to the bottom in a short period of time and the surface tension cannot cope with this metal. In addition the high temperature from both heat sources is transported intermittently to the root side. Insufficient energy at the bottom of the joint resulted in insufficient wetting of the liquid metal with the bottom surfaces of the pipes and leads to sagging. The excessive metal deposited by the arc source was being pushed by the recoil pressure and the electromagnetic force and released periodically. Eventually the pressure exceeded the surface tension and the metal could break through, but because the metal was delivered under high pressure, much higher than the surface tension, it had been expelled. In addition, the insufficient temperature at the root side to provide wetting of the transported liquid metal with the inner walls exacerbated the problem. The instabilities occurred periodically, depending on the volume of deposited wire, welding speed and energy input.

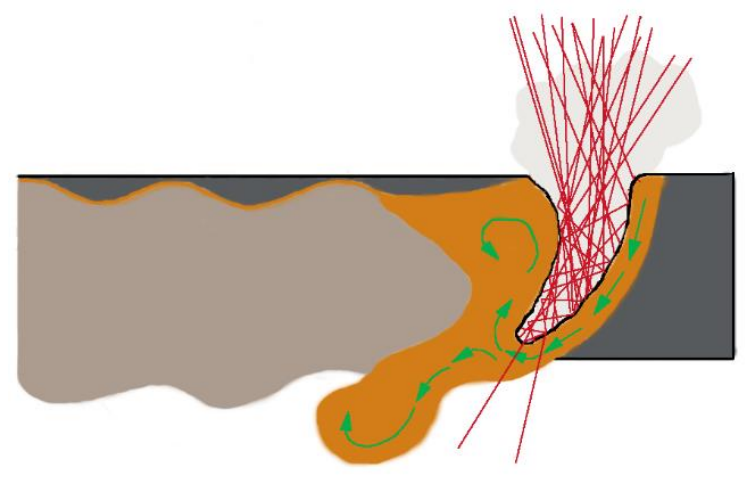

Figure 8: Schematics of melt flow in case of insufficient energy

The effect shown in Figure 6 and Figure 8 is counterintuitive, because it may suggest excessive penetration caused by an excessive energy input, but actually it is caused by an insufficient energy input. As shown in Figure 9 and Figure 10 a further increase of the laser power from $7.7 \mathrm{~kW}$ to $8.2 \mathrm{~kW}$ resulted in full penetration and consistent root profile. The plume visible on the video image suggests the full penetration and a fully developed keyhole. The metal solidifying behind the heat source exhibits smooth profile. Macrograph in Figure 10 shows good root profile and much more metal at the top bead of this bevel, which indicates less material waste, as compared to the previous 
case. Also the weld width at half thickness is higher in this case as compared to Figure 7. Note that these are root pass welds, therefore the joints were not intended to be fully filled with the weld metal.

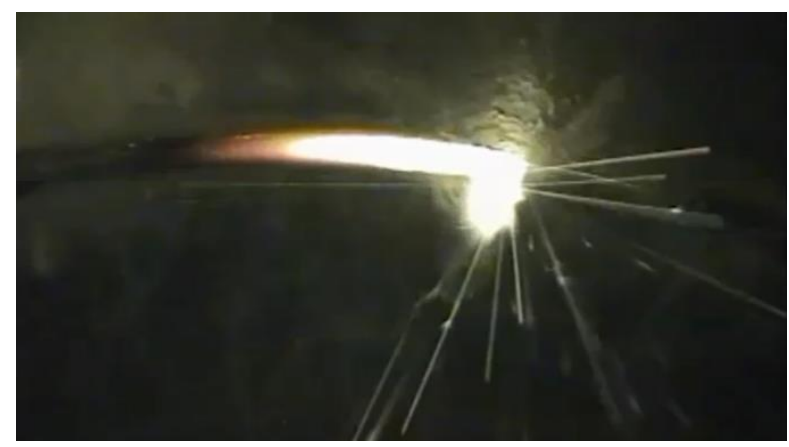

Figure 9: Root formation at $8.2 \mathrm{~kW}$ of laser power and 7.4 kW arc power (WFS $12 \mathrm{~m} / \mathrm{min}$ )

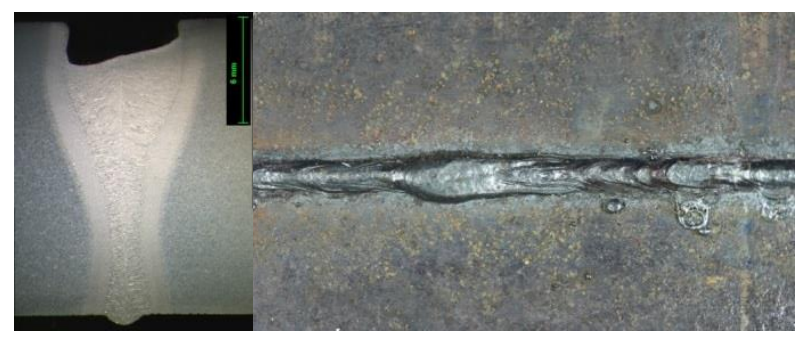

Figure 10: Macrograph and picture of root at $8.2 \mathrm{~kW}$ laser power and $7.4 \mathrm{~kW}$ arc power (WFS $12 \mathrm{~m} / \mathrm{min}$ )

The same effect could be achieved by increasing the arc current and arc power as a result, which is shown in Figure 11. The electromagnetic force of arc, which is dependent as a square of current, enhanced the recoil pressure of the laser and helped develop the keyhole and balance the pressure. In this case the arc power was increased quite significantly, which resulted in more penetration, exhibited as bright plume and spatter inside the pipe. Macrograph and root profile shown in Figure 12 suggest that much more heat has been transported to the bottom of this joint, which resulted in good wetting between the liquid metal and the parent metal. The root profile is wide and smooth in this case. However the electromagnetic force of arc is more difficult to control than the laser recoil pressure and high current may result in erratic arc and unstable metal transfer, therefore it is better to control the process by controlling the power density of a laser.
Increasing energy of arc or laser triggers two effects. Firstly the pushing force for the liquid metal, which is the recoil pressure in the case of laser and the electromagnetic force the in case arc, results in more efficient transport of the heat to the bottom of a joint. The system is in steady state and the liquid metal is being continuously delivered and the pressure is well balanced. Secondly a higher energy input provides more heat to the meltpool and hence increases the likelihood of good wetting at the bottom of the joint. In Figure 13 thermal-profiles measured at different positions of heat affected zone (Figure 5) for a weld with unstable root profile is shown. It can be seen that only one thermocouple located in a half way through the thickness recorded temperature closed to the melting point. In contrast in Figure 14 the same temperature was achieved at all positions by increasing the arc power and electromagnetic force, indicating more efficient transport of heat to the bottom of the joint. This higher temperature could contribute to the improved wetting of the liquid metal with the parent material and better root profile.

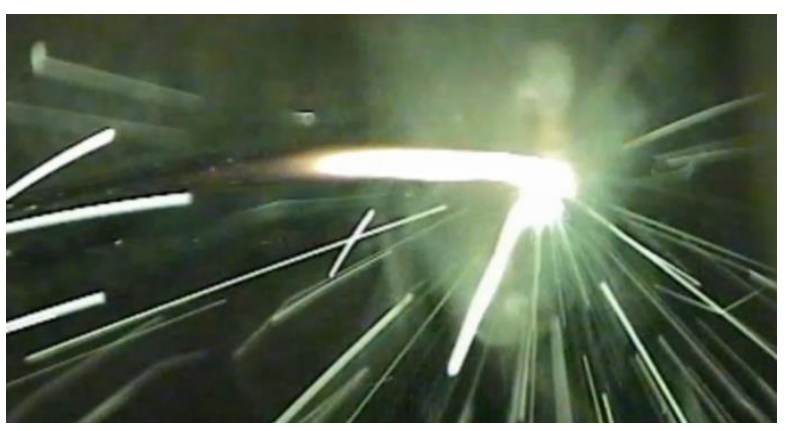

Figure 11: Root formation at $7.7 \mathrm{~kW}$ of laser power and $12.1 \mathrm{~kW}$ arc power (WFS $20 \mathrm{~m} / \mathrm{min}$ )

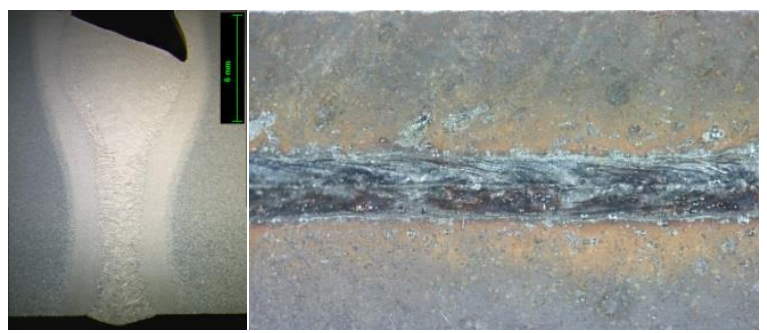

Figure 12: Macrograph and picture of root at $7.7 \mathrm{~kW}$ laser power and $12.1 \mathrm{~kW}$ arc power (WFS $20 \mathrm{~m} / \mathrm{min}$ ) 


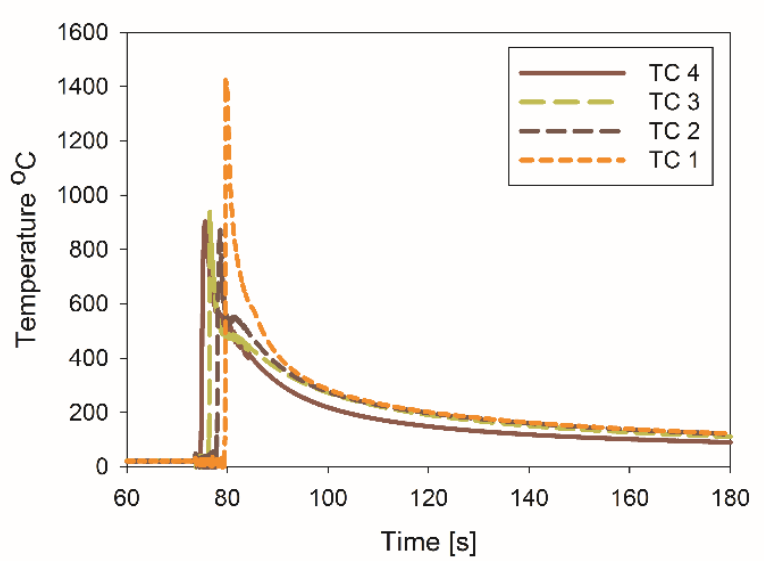

Figure 13: Thermal cycle measured at different positions according to Figure $5 ; 8.2 \mathrm{~kW}$ laser power, $7 \mathrm{~kW}$ arc power (WFS $12 \mathrm{~m} / \mathrm{min}$ )

As shown schematically in Figure 15, fully penetrated keyhole in a continuous manner provides continuous flow of the liquid metal without any periodic disturbances. The parent metal at the bottom receives heat directly form the laser beam and indirectly through the liquid metal. And if the temperature of the surface at the bottom is sufficient and the pressure of delivered metal stable, the transported metal can then be subsumed and utilised to form the root, provided that surface tension can support the liquid metal.

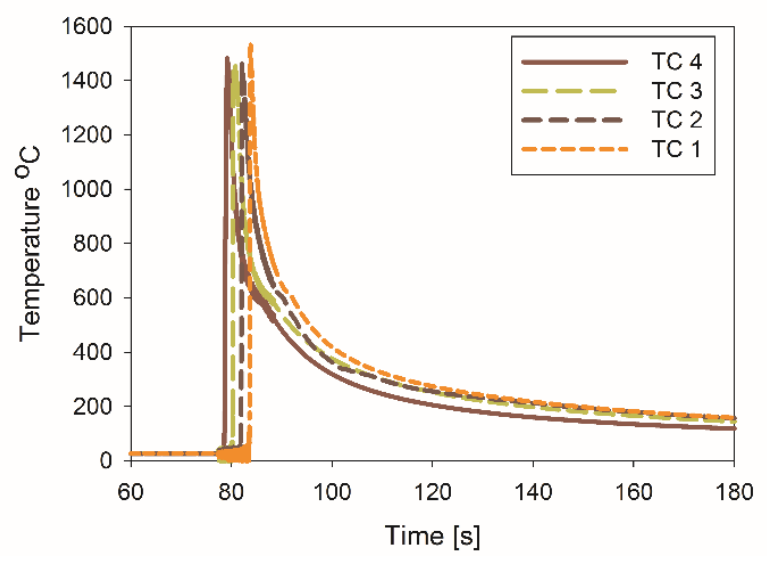

Figure 14: Thermal cycle measured at different positions according to Figure $5 ; 8.2 \mathrm{~kW}$ laser power, $12 \mathrm{~kW}$ arc power (WFS $20 \mathrm{~m} / \mathrm{min}$ )

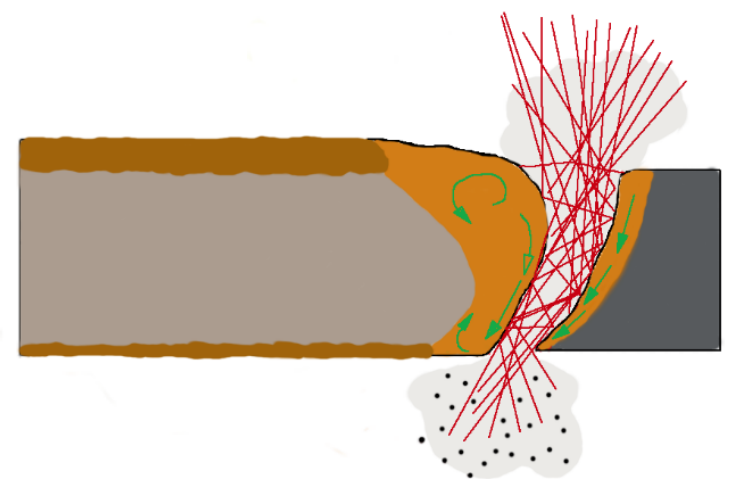

Figure 15: Schematics of melt flow in stable root scenario

A further increase of the energy resulted in excessive penetration force and led to significant spatter inside the pipe, as shown in Figure 16. In this case both the laser power and the arc power were increased. However macrograph and picture of the root in Figure 17 show that, despite this excessively high energy, the root did not collapse. The pore exhibited in this macrograph, indicates very high temperature and high pushing pressure, but the root profile is still intact.

This indicates high tolerance of hybrid process with respect to the applied energy and its effect on the weld profile. Note that in this welding position $(2 \mathrm{G})$ the gravitational force was excluded hence the high tolerance of the process. In $1 \mathrm{G}$ welding position, in contrast, the process is more sensitive and the applied energy and temperature of the meltpool have to be controlled more strictly to avoid sagging.

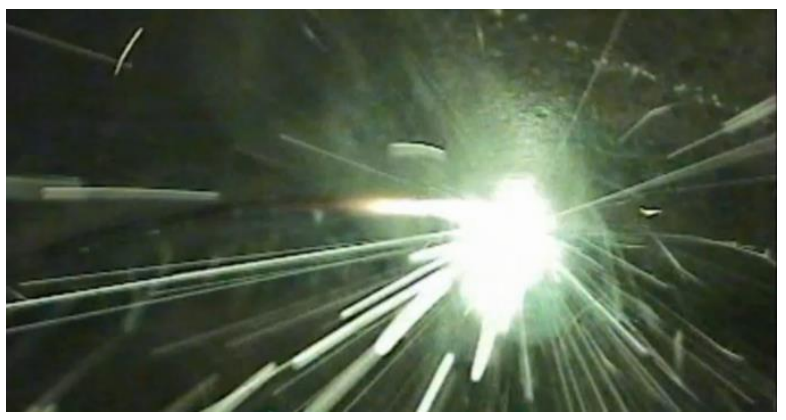

Figure 16: Root formation at $8.2 \mathrm{~kW}$ of laser power and $11.8 \mathrm{~kW}$ arc power (WFS $20 \mathrm{~m} / \mathrm{min}$ ) 


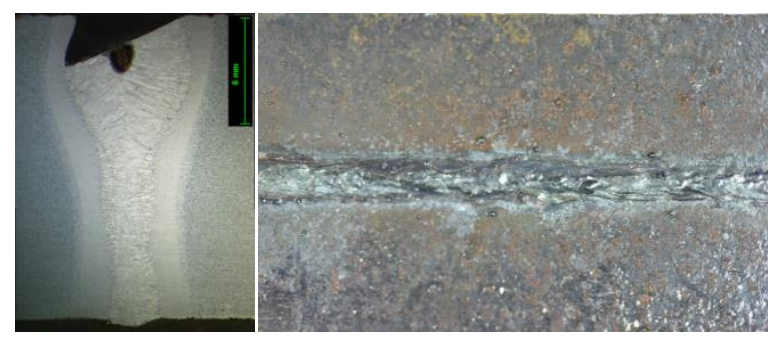

Figure 17: Macrograph and picture of root at $8.2 \mathrm{~kW}$ laser power and $11.8 \mathrm{~kW}$ arc power (WFS $20 \mathrm{~m} / \mathrm{min}$ )

\section{Conclusions}

Root formation was studied in $2 \mathrm{G}$ hybrid laser GMAW welding of pipes. It has been found that insufficient energy and penetration force can lead to unbalanced pressure between the recoil pressure and the surface tension resulting in intermittent bursts of the liquid metal at the root side. This also causes intermittent transfer of the heat down to the root causing insufficient temperature and poor wetting at the root, evident as severe under-cut of the top bead and sagging of the root. Increasing energy, either by increasing the arc current or the laser power improves the root profile, which is attributed to fully developed keyhole and as a result better pressure balance and the improved wetting between the liquid metal and the bottom surface. It has been also shown that even with too high energy input the root did not collapse in this welding position and an acceptable weld profile was achieved. This means that to achieve a good weld profile an excessive energy is required, which is in excess to the energy needed just to penetrate the workpiece. This extra energy ensures steady state conditions of pressure and heat transfer needed for good weld profiles.

\section{Acknowledgment}

This research was carried out under project number M31.8.12461 in the framework of the Research Program of the Materials Innovation Institute M2i (www.m2i.nl). Authors are also grateful to Heerema Marine Contractors (www.hmc.heerema.com) as the industrial partner of the project.

\section{Bibliography}

1. Metzbower, E.A., et al., Thermal analysis and microhardness mapping in hybrid laser welds in a structural steel, in Materials Science Forum. 2003. p. 41474152.

2. Dithey, U. and A. Wieschemann, Prospects by combining and coupling laser beam and arc welding processes. International Institute of Welding, IIW Doc. XII-1565-99 1999.

3. Ribic, B., T.A. Palmer, and T. DebRoy, Problems and issues in laser-arc hybrid welding. International Materials Reviews, 2009. 54(4): p. 223-244.

4. Colegrove, P., et al., Welding process impact on residual stress and distortion. Science and Technology of Welding and Joining, 2009. 14(8): p. 717-725.

5. Semak, V. and A. Matsunawa, The role of recoil pressure in energy balance during laser materials processing. Journal of Physics D: Applied Physics, 1997. 30(18): p. 2541-2552.

6. Zhou, J., H.L. Tsai, and P.C. Wang, Transport phenomena and keyhole dynamics during pulsed laser welding. Transactions of the ASME, 2006. 128(July 2006): p. 680.

7. Kaplan, A., Model of deep penetration laser welding based on calculation of the keyhole profile. Journal of Physics D: Applied Physics, 1994. 27(9): p. 18051814.

8. Mills, K.C., et al., Marangoni effects in welding. Philosophical Transactions of the Royal Society A: Mathematical, Physical and Engineering Sciences, 1998. 356(1739): p. 911-925.

9. Golubev, V.S. Laser welding and cutting: Recent insights into fluid-dynamics mechanisms. in Proceedings of SPIE - The international Society for Optical Engineering 5121 (2002) p. 1-15.

10. Amara, E.H., R. Fabbro, and F. Hamadi, Modeling of the melted bath movement induced by the vapor flow in deep penetration laser welding. Journal of Laser Applications, 2006. 18(1): p. 2-11. 
11. Matsunawa, A. and V. Semak, The simulation of front keyhole wall dynamics during laser welding. Journal of Physics D: Applied Physics, 1997. 30(5): p. 798809.

12. Tenner, F., et al., Experimental and numerical analysis of gas dynamics in the keyhole during laser metal welding. Physics Procedia, 2014. 56: p. 1268-1276.

13. Cho, J.H. and S.J. Na, Three-dimensional analysis of molten pool in GMA-laser hybrid welding. Welding Journal (Miami, Fla), 2009. 88(2): p. 35s-43s.

14. Zhou, J. and H.L. Tsai, Investigation of mixing and diffusion processes in hybrid spot laser-MIG keyhole welding. Journal of Physics D: Applied Physics, 2009. 42(9) p. 1-15.

15. Avilov, V., et al., Full penetration laser beam welding of thick duplex steel plates with electromagnetic weld pool support. Journal of Laser Applications, 2016. 28(2).

16. Mirakhorli, F., et al., Hybrid Laser-Arc Welding of 10-mm-Thick Cast Martensitic Stainless Steel CA6NM: As-Welded Microstructure and Mechanical Properties. Metallurgical and Materials Transactions A: Physical Metallurgy and Materials Science, 2016: p. 3545-3563.

17. Feng, J., et al., Narrow gap laser welding for potential nuclear pressure vessel manufacture. Journal of Laser Applications, 2016. 28(2).

18. Elmesalamy, A.S., et al., Understanding the process parameter interactions in multiple-pass ultra-narrow-gap laser welding of thick-section stainless steels. International Journal of Advanced Manufacturing Technology, 2013. 68(14): p. 1-17.

19. Elmesalamy, A., J.A. Francis, and L. Li, $A$ comparison of residual stresses in multi pass narrow gap laser welds and gastungsten arc welds in AISI 316L stainless steel. International Journal of Pressure Vessels and Piping, 2014. 113: p. 49-59.

20. Havrilla, D., et al. Advanced welding techniques with optimized accessories for high brightness $1 \hat{I} 1 / 4 m$ lasers. in ICALEO 2013 - 32nd International Congress on
Applications of Lasers and Electro-Optics. 2013. 


\title{
Cranfield University
}

CERES https://dspace.lib.cranfield.ac.uk

2017-05

\section{Root stability in hybrid laser welding}

\author{
Suder, Wojciech
}

Laser Institute of America

Wojciech Suder, Supriyo Ganguly, Stewart Williams and Bagus Yudodibroto. Root stability in hybrid laser welding. Journal of Laser Applications, Volume 29, Issue 2, article number 022410 (2017) http://dx.doi.org/10.2351/1.4983161

Downloaded from Cranfield Library Services E-Repository 